\title{
The Blade of Auditing Chopped up the Public Funds Misappropriation: A Case Study of Hotel Industry
}

\author{
Benxiang Jiang \\ Zibo Municipal Investment Audit Center, Zibo, China \\ Email: xiqijiang@outlook.com
}

How to cite this paper: Jiang, B. X. (2021). The Blade of Auditing Chopped up the Public Funds Misappropriation: A Case Study of Hotel Industry. American Journal of Industrial and Business Management, 11, 1237-1242.

https://doi.org/10.4236/ajibm.2021.1112074

Received: November 22, 2021

Accepted: December 24, 2021

Published: December 27, 2021

Copyright $\odot 2021$ by author(s) and Scientific Research Publishing Inc. This work is licensed under the Creative Commons Attribution International License (CC BY 4.0).

http://creativecommons.org/licenses/by/4.0/

\begin{abstract}
For a long time, financial audit has been highly valued by relevant government departments, and the relevant cases have aroused strong social repercussions. In this paper, we conduct a study on a hotel finance department manager public funds misappropriation case. During the whole investigation process, analytical reviews are carried out throughout the case. More importantly, the professional judgment of audit has been closely combined with the psychological changes of the leaders and related personnel of the audited entity to catch audit clues in time. By taking advantage of relevant personnel ambivalence and work omissions, we timely grasp a whole picture of the situation to further promote the audit work.
\end{abstract}

\section{Keywords}

Financial Audit, Misappropriation of Public Funds, Case Study

\section{Introduction}

Audit supervision plays a more and more important role in protecting state-owned assets and combating corruption, and has become an important part of the national supervision system. Recently, Zibo City Intermediate People's Court hosted the open trial and made a judgment of first instance for a hotel finance department manager public funds misappropriation case which was reported by our bureau, the defendant was sentenced to 20 years in prison. It was the case that imposed the heaviest penalty in our city's auditing history. It was also the first case of criminal punishment handed over by audit in the past decade. So how did the auditors deal with this major audit case? The audit of the unit was arranged urgently by the municipal government according to the overall layout 
of the integration of the city's service resources. This paper's research structure is as follows: early coordination before action, verifying the details, finding the breakthrough, extension for results searching, and effective measures to deal with emergency.

\section{Good Coordination and Early Action}

The audit of the hotel was arranged urgently by the municipal government according to the overall layout of the integration of the city's service resources, which is a normal government temporarily assigned auditing affair required to be completed in seven days. According to the unified arrangement of the government, the audit work is carried out simultaneously with the verification of assets by the state assets management department (Wu, 2020; Zhang \& Zhou, 2018; Huang, 2016). In order to improve working efficiency, the two departments consulted in advance, simultaneously started the auditing progress, divided the work in a short time, had timely communication and data sharing. During the implementation of the auditing, our bureau has taken several high-performance working measures, the first one was simultaneously starting the auditing progress. After the special meeting of the municipal government arranging, in accordance with the thirty-eighth provisions of the Audit Law, the municipal government shall directly carry out the audit with the notice of audit in the next day (Fang and Huang, 2016). The second was declaring the discipline, funds were temporarily frozen, and all funds must be approved by the joint task force (Jiang, 2014; Song, 2012). The third working measure was to require the date of the government meeting as the deadline (the 21st day of the same month), conducted the annual income and expenditure settlement and accounting statements, and provided the latest three years of accounting data and related information at the same time for avoiding changes. The Fourth working measure was collected and managed the official seal, contract seal and financial seal by the working group, and the economic activities during the audit period, especially the activities of income and expenditure of funds, shall be subject to audit supervision.

\section{Strictly Verifying the Details}

Based on preliminary audit investigation and analytical judgment, the results show that some relevant internal control systems were not strictly implemented, assets and liabilities were not standardized, there were many funds have been involved in litigation cases, the hotel had opened too many bank accounts, and they cannot provide proof of account opening and statement etc., were highly doubtful via auditing which had high auditing risks. For example, according to preliminary statistics, a total of 21 illegal bank accounts were opened, including 8 accounts that had been closed and could not provide proof of expense accounts, 5 accounts that could not provide statement of accounts, and there were also phenomena that the income and expenditure of expenses, commodity sales, 
loans and other funds were not recorded in the account. We started from the key control points of internal control, combined with the characteristics of business operation, attacked the focus of work, verified the financial situation from the details, carefully checking major assets, debts, and key funds. We are required to send special personnel from the hotel to assist the audit team. For verifying major revenue and expenditure, there shall be carried out in three goals which are arriving at the site, going the auditee's working place and meeting the responsible person. In case of the individual departments of the audited units cannot provide timely information, unclear responsibilities and other problems, requiring the unit responsible for timely coordination, business departments and specific handling personnel ought to actively coordinate in order to ensure the timely implementation of the auditing.

\section{Finding the Breakthrough under Resistance}

In the process of intense auditing work, just at the critical moment that the financial department, the relevant personnel of the audited unit and the audit team were verifying the relevant situation, the financial responsible person disappeared from the audit site. However, many questions needed to be answered urgently, and others did not know the situation, auditing work temporarily bogged down. We urged the hotel and sent people to look for the person but the result came to nothing. Our professional sensibilities tell us that something may be wrong. From the second day on, we had quickly sorted out relevant clues and immediately reported the situation and difficulties encountered in the audit to the bureau leaders. After careful consideration, the bureau leaders took prompt and decisive measures. Firstly, formally notifying the main responsible person of the audited organization, requested to contact the financial responsible person quickly, and took remedial measures, and actively cooperated with the audit work. Secondly, strengthened organizational leadership and the audit force, command forward, strengthened dispatching, strived for the cooperation and got supports from all parties, kept the situation informed at any time, solved work difficulties in a timely manner, strengthened logistics support and technical support. Thirdly, adjusting the direction of audit work, strengthened the analysis of the overall operating conditions of the auditee and the points out of control of internal control system, increased the intensity of external assignment, sudden implementation of key clues, search for audit evidence, paid attention to audit confidentiality, and maintained a tight inside and loose outside the working state.

\section{Fast Extension for Results Searching}

In the process of sudden analysis and implementation of key clues, the management of special funds allocated by the financial department has attracted our high attention. We started from the bank account of the fund allocated by the financial department, first obtained the statement of the opening bank, checked 
the receipt of the funds one by one, and directly extended the implementation of doubtful payments to the bank. During the auditing process, we found that a sum of RMB 802.91 million was transferred from ICBC to the account of the unit in agricultural Bank of China by withdrawal transferring method, but the book of the unit did not reflect the income of the fund. With the cooperation of the bank staff, the auditor obtained some preliminary certification materials at that night. In the next morning, we went to the Agricultural Bank of China to continue to confirm the whereabouts of the funds, and checked the corresponding funds transferred from the agricultural Bank account. It was found that a sum of 7.7891 million yuan had been transferred to a credit card opened by Hua Wang (a pseudonym) at China Citic Bank. Who is Hua Wang? With questions and acquired clues, we met with the person in charge of the audited unit for the first time in the morning. The person in charge confirmed that Wang Hua was a financial staff member of the unit, but did not know about the transferred funds. If it is not the private funds of the organization, is there something else hidden? Carrying with the doubt, we asked to meet with Hua Wang. According to Hua Wang description, this bank card was opened by finance department head with Hua Wang's individual ID copy, credit card and password were mastered by financial department responsible person. Hua Wang said she was not aware of the card's specific fund receipts and expenditures as well as the whereabouts of the person in charge of finance. At that time, it was nearly noon. Under the condition that the auditors could directly inquire about the account opening of individual banks, we asked Hua Wang to assist in inquiring about the account opening and income and expenditure of the card. The audit team and Hua Wang went to China Citic Bank to check the balance of the card and printed the bank statement. The audit found that the credit card account was opened on June 30, 2009, and the balance of the credit card deposit was 4.31 yuan until the audit date, and the accumulated capital expenditure from the account to the audit date was 24,361,500 Yuan. After the audit team returned to the auditee, we immediately found the main person in charge to further understand the situation, but the person in charge denied knowing anything again.

\section{Effective Measures to Better Achieve the Goal}

Auditors have overcome all kinds of resistance, verified the situation with relevant personnel, through the bank in each agency more than ten times of interspersed extended investigation. And according to the external transfer situation, we communicated with the organization's leader three times and organized the relevant personnel to verify this problem, and make the relevant written statement in a short morning time. Through the joint efforts, a misappropriation case involving embezzlement of 7.7891 million yuan surfaced was coming into focus. If it is handled according to the routine audit procedures, it will delay a lot of time until the audit team finds out all the truth, which may cause incalculable consequences and economic losses. As an emergency case, we reported to the 
bureau's main leaders in a timely manner, and in accordance with the requirements, quickly formed written materials, in the afternoon to the city's relevant leaders and departments to report, in which the audit team temporarily broke the routine in the event of the disappearance of key involved personnel. Then, relevant evidence was handed over to the judicial department, which provided important clues and basis for the rapid investigation of the case. The suspects involved were quickly tracked down and brought to justice, and relevant funds are being recovered.

\section{Reviewing Files for Reflection}

Looking back on the whole auditing process, I was inspired a lot and summarized the following ideas for reflection. Overall, the root cause of this public funds misappropriation case is the temptation from money. Firstly, audit should form an intense authority. The whole audit team is supposed to have strong team-work spirit and maintain a high level of internal consistency, especially at the critical moment of audit implementation, each member should keep an appropriate distance from the auditee and relevant staff to ensure the impartiality of the audit. During the work, auditors ought to have conscientious and pragmatic working spirits. It is necessary to have the tenacity just like the Chinese poem writing that biting the mountain green and won't let go. There should be excellent integrity and self-discipline for protection, achieving that fairness fosters discernment and integrity creates authority to convince the audited entity. It is also significant to establish the authority of auditors, maintain the image of audit institutions. Secondly, auditors should demonstrate the professional auditing expertise and stability. Facing problems, it is also the moment when auditors and audited personnel show their professional ethics, which requires auditors' selfless dedication and fighting spirits. Meanwhile, it is also a challenge to the comprehensive emergency response capacity of agencies. In this audit case, it showed the comprehensive guarantee ability of organization and leadership forming by computer science, laws and regulations, transportation and other aspects which provided strong backing and support for the audit team to push forward the audit work. Thirdly, we should always pay attention to grasp the skills of handling audit affairs. During the process of investigating, in addition to strengthening the analytical review of accounting materials, professional judgment of auditing should be closely combined with the psychological changes of the leaders and related personnel of the audited units. The audit information and clues mastered shall be appropriately disclosed to the relevant personnel and the enthusiasm of all parties concerned is supposed to be aroused.

During the whole investigation process, analytical reviews are carried out throughout the case. More importantly, the professional judgment of audit should be closely combined with the psychological changes of the leaders and related personnel of the audited entity to catch audit clues in time. By taking advantage of relevant personnel ambivalence and work omissions, timely grasp a 
whole picture of the situation to further promote the audit work.

\section{Conclusion}

In this paper, we conduct a study on a hotel finance department manager public funds misappropriation case. The major conclusions are as follows. The root cause of this public funds misappropriation case is the temptation from money. Audit should form an intense authority. The whole audit team is supposed to have strong team-work spirit and maintain a high level of internal consistency. Auditors should demonstrate the professional auditing expertise and stability. Auditors should always pay attention to grasp the skills of handling audit affairs.

\section{Conflicts of Interest}

The author declares no conflicts of interest regarding the publication of this paper.

\section{References}

Fang, Z., \& Huang, S. (2016). Analysis on How to Investigate and Deal with the Crime of Misappropriation of Public Funds. China Audit Journal, 7, 1-3.

Huang, L. (2016). On Audit Evidence Collection Skills of Embezzlement Crime. China Audit Journal, 7, 1-2.

Jiang, L. (2014). Analysis on How to Define Corruption in Audit. China Audit Journal, 7, 1-2.

Song, X. (2012). Problems Needing Attention in Audit Transfer of Suspected Embezzlement of Public Funds. China Audit Journal, 7, 1-2.

Wu, Y. (2020). Analysis of a Case of Embezzlement of Public Funds by Privately Setting up a "Small Treasury". China Audit Report, 7, 1-2.

Zhang, W., \& Zhou, S. (2018). Analysis on the Constitutive Elements of the Crime of Misappropriation of Funds. China Audit Journal, 7, 1-3. 